This is the peer reviewed version of the following article:

Brooks, J. and Guttridge, T. and Franks, B. and Grubbs, R. and Chapman, D. and Gruber, S. and Di Battista, J. et al. 2016. Using genetic inference to re-evaluate the minimum longevity of the lemon shark Negaprion brevirostris. Journal of Fish Biology. 88 (5): pp. 2067-2074., which has been published in final form at http://doi.org/10.1111/jfb.12943

This article may be used for non-commercial purposes in accordance with Wiley Terms and Conditions for Self-Archiving at http://olabout.wiley.com/WileyCDA/Section/id-828039.htm|\#terms 

列

\section{Using genetic inference to re-evaluate the minimum longevity of the lemon shark, Negaprion brevirostris}

Brooks, J.L., Guttridge, T. L., Franks, B. R., Grubbs, D. R., Chapman, D. D., Gruber, S.H., Dibattista, J. D., Feldheim, K.A. 7

Author to whom correspondence should be addressed :Brooks, J. L., Bimini Biological Field

Station Foundation, South Bimini, Bahamas and Fish Ecology and Conservation Physiology Lab, Carleton Technology and Training Centre, Carleton University, 1125 Colonel By Drive, Ottawa, ON, Canada K1S 5B6. jillbrooks85@gmail.com Tel. +1 6136005895

2 Guttridge, T. L. Bimini Biological Field Station Foundation, 15 Elizabeth Dr., South Bimini, Bahamas.

4 Franks, B. R. Department of Biology, Florida Southern College, Lakeland, Florida, USA.

Grubbs, R. D., FSU Coastal and Marine Laboratory, 3618 Coastal Highway 98, St. Teresa, FL, $32358-2702$, USA

7 Chapman, D. D., School of Marine and Atmospheric Sciences, Stony Brook University, Stony Brook, NY, 11794-5000, USA 
19 Gruber, S. H., Bimini Biological Field Station, South Bimini, Bahamas and Division of Marine

20 Biology and Fisheries, Rosenstiel School of Marine and Atmospheric Science, 4600

21 Rickenbacker Causeway, Miami, Florida 33149, U.S.A.

22 DiBattista, J. D., Department of Environment and Agriculture, Curtin University, PO Box

23 U1987, Perth, WA 6845, Australia

24 Feldheim, K.A., Pritzker Laboratory for Molecular Systematics and Evolution, Field Museum of 25 Natural History, 1400 South Lake Shore Drive, Chicago, IL 60605, USA

Accurate life history parameters are critical for effective fisheries management, in particular,

29 knowing the maximum life span of a species. Here we use a combination of mark-recapture and 30 genetic sampling to extend the minimum longevity of an elasmobranch species. Using this

31 approach, life span estimate of the lemon shark, Negaprion brevirostris, was increased

32 conservatively from 20.2 years to 37 years. This increase in longevity means higher vulnerability 33 and a longer recovery time from exploitation.

35 Key Words: Fishery Management; Life Span; Natural Mortality; Mark-recapture; Genetic 36 Pedigree.

37

Author to whom correspondence should be addressed: jillbrooks85@gmail.com Tel. +1 6136005895 
Accurately modeling population dynamics is impossible without an understanding of how fast individuals are naturally removed from the population, and how many offspring they produce over a lifetime, both of which are influenced by life span (Hoenig, 1983). Life spans of long-

41 lived fishes are often underestimated, which has implications for calculating natural mortality

42 rates and intrinsic rebound potentials and can lead to mismanagement of stocks (Cailliet and

43 Andrews, 2008). If a species is longer-lived than originally modelled, for example, life-time

44 fecundity is underestimated, but instantaneous rates of natural mortality are overestimated.

45 Across shark species, population productivity is negatively correlated with maximum

46 reproductive age (Smith et al., 1998), therefore an increase in the known maximum age within a

47 population suggests the stock is actually more vulnerable to overexploitation.

48 Several methods for validating age have been developed and applied to sharks and batoids

49 (elasmobranchs; Campana, 2001). Traditional age determination techniques involve analyzing

50 growth rings in vertebral centra, dorsal fin spines and caudal thorns (Brown \& Gruber, 1988;

51 Cailleit et al., 2006). However, considerable variability exists in calcification patterns, and thus

52 the utility of aging techniques, within and among taxonomic groups of elasmobranchs (Goldman, 53 2005). The precision (verification) and accuracy (validation) of aging techniques should be 54 assessed in all studies (see review by Cailliet et al., 2006) using determinate methods such as 55 mark-recapture of known-age or chemically tagged fish or dating using lead:radium or bomb 56 radiocarbon, or through indeterminate methods such as marginal increment analysis (Beamish \& 57 McFarlane, 1983; Brown \& Gruber, 1988; Campana, 2001). Age estimation of older sharks 58 using band pairs is also less accurate due to a decrease in somatic growth, leading to a decrease Author to whom correspondence should be addressed: jillbrooks85@gmail.com Tel. +1 6136005895 
59 in the rate of deposition of vertebral material (Francis et al., 2007; Andrews et al., 2011; Hamady

60 et al., 2014). Many original life span estimates have been re-evaluated using bomb radiocarbon

61 methods and have often been revised upwards substantially (Campana, 2001; Cailliet \&

62 Andrews, 2008).

64 The lemon shark Negaprion brevirostris (Poey, 1868) is a large coastal shark that is found on

65 both sides of the Atlantic Ocean and the Eastern Pacific, where it is exploited by recreational and

66 commercial fisheries (Compagno 1984; Carlson et al., 2012; Shiffman \& Hammerschlag, 2014).

67 Brown \& Gruber (1988) used vertebral centra to age 110 N. brevirostris in Florida, U.S.A. and

68 Bimini, Bahamas. Annual band deposition on the vertebrae was validated through mark-

69 recapture of chemically-tagged individuals. Of the 110 animals aged, the oldest estimated was

7020.2 years for a $226 \mathrm{~cm}$ pre-caudal length $\left(L_{\mathrm{PC}}\right)$ male. The study suffered, as many do, from low

71 sample sizes and hence the growth curve did not asymptote. Hoenig \& Gruber (1990) estimated

72 that the theoretical maximum age for lemon sharks was 26 years since the largest specimens

73 from the Brown \& Gruber (1988) study were considerably smaller than the maximum reported

74 size. It was hypothesized that the maximum longevity for lemon sharks had been largely

75 underestimated and could be extended using previously documented age at maturity (Brown \&

76 Gruber, 1988), and an extensive genetic pedigree of offspring within the nurseries (Feldheim et 77 al., 2014).

Author to whom correspondence should be addressed: jillbrooks85@gmail.com Tel. +1 6136005895 
Adult female N. brevirostris were aged in one of two ways: parental genotype reconstruction or

79 parental genotype reconstruction combined with tag-recapture. Parental genotype reconstruction

80

81

82

\section{3}

84 involved exhaustively sampling 0-3 year old $N$. brevirostris at Bimini $\left(25^{\circ} 44^{\prime} \mathrm{N}, 79^{\circ} 18^{\prime} \mathrm{W}\right)$,

Bahamas, every year since 1993 (Feldheim et al., 2014). Sampling occurred each June using monofilament gillnets (180 m length, $2 \mathrm{~m}$ height) set perpendicular from shore. All captured $N$. brevirostris were measured $(\mathrm{cm})$ for pre-caudal length $\left(L_{\mathrm{PC}}\right)$, fork length $\left(L_{\mathrm{F}}\right)$ and total length $\left(L_{\mathrm{T}}\right)$, sex determined, and tagged with a passive integrated transponder tag (PIT, Destron Fearing, South St. Paul, MN, USA). See Gruber et al., 2001, for a full description of methods. A small piece of fin was removed and stored in $20 \%$ DMSO solution for genetic analysis. Individuals were released alive after a brief holding period of no more than 7 days (Feldheim et al., 2014). DNA from all $N$. brevirostris were genotyped at 11 polymorphic microsatellite markers followed by sibship and parental genotype reconstruction (for detailed methods see Feldheim et al., 2002a; Wang, 2004; DiBattista et al., 2008; Feldheim et al., 2014). Genetic profiling of $N$. brevirostris from 20 consecutive cohorts (1993-2012), showed that certain females faithfully gave birth at this site for nearly two decades (Feldheim et al., 2014). This enabled estimation of minimum age of these individuals, with the conservative assumption being made that their first genetically confirmed litter in Bimini was their first litter. Brown \& Gruber (1988) estimated age of maturity of 12.7 years with first parturition at 14 years, which was concordant with direct observations of philopatric females of known age first returning to Bimini for parturition (Feldheim et al., 2014). This study, therefore, conservatively estimated the age of 19 females that gave birth multiple times at Bimini by assuming that they were age 14 years the first year we sampled any of their offspring, and died the last year we sampled any of their offspring. Author to whom correspondence should be addressed: jillbrooks85@gmail.com Tel. +1 6136005895 
101 Tag recapture was also used to directly estimate age of one tagged female. Gravid females are 102 annually targeted for capture in late March and April, as they enter the Bimini lagoon as part of 103 an ongoing study of natal philopatry. Individuals were either captured by closely following the 104 shark from a skiff in shallow water $(<2 \mathrm{~m}$ depth), then placing a dip-net on its snout to incite it 105 to bite the mesh and become tangled, or encircling the shark with a large seine net deployed from 106 two small skiffs. Individuals were fitted with National Marine Fisheries Service (NMFS) M-type 107 dart tags (Kohler et al., 1998) and tagged with electronic PIT tags unless they were already 108 tagged.

109 Parental genotype reconstruction (Feldheim et al., 2014) revealed that at least 19 female $N$. 110 brevirostris giving birth at Bimini were older than Brown \& Gruber's (1988) oldest individual

111 (Table I), including B-female 12, estimated to be at least 37 years old when last detected.

112 A mature female $N$. brevirostris with fresh mating wounds was captured using the netting 113 method on May 20th, 2014. A Vemco ® V16-6H tag was surgically implanted into the body 114 cavity (see Kessel et al., 2014 for method).The shark had a broken NMFS dart tag and an intact 115 PIT tag, (ID A4D11). Records indicate that her first capture was 17 years earlier on April 18th, 116 1997, at a site less than $8 \mathrm{~km}$ away (Figure 1), with $L_{\mathrm{PC}}(196 \mathrm{~cm})$ and $L_{\mathrm{T}}(252 \mathrm{~cm})$, and a bulging 117 abdomen with movement of pups indicating this shark was pregnant at the time. The second 118 capture of this shark was on April 28th, 2005, and again, she was suspected to be pregnant. 119 According to the sibship pedigree (Feldheim et al., 2014), a total of 65 of her pups have been Author to whom correspondence should be addressed: jillbrooks85@gmail.com Tel. +16136005895 
120 sampled on a biennial basis between June 1997 and June 2013 (Table II). Brown \& Gruber

121 (1988), estimated age of maturity of 12.7 years and first parturition at 14 years, which is

122 concordant with Feldheim et al. (2014). Based on this, A4D11 was at least 31 years old when

123 captured in 2014, and 32 years old when she was detected on multiple Vemco $®$ acoustic

124 receivers in Bimini waters in April, 2015 (Guttridge, T. L. pers. observation). This shark had a

125 pre-caudal length measurement of $203 \mathrm{~cm}$ in 2014; however, $23 \mathrm{~cm}$ smaller than the 20.2 year

126 old male sampled by Brown \& Gruber (1988).

127 This study provides the first example of using genetic pedigree reconstruction and mark-

128 recapture to estimate the age of a chondrichthyan fish. It revises the minimum longevity of $N$.

129 brevirostris by nearly a factor of two from 20.2 years to 37 years, however, actual life span could

130 be longer. For example, genetic sampling of N. brevirostris in Bimini began in 1990; 'B-Female

131 12' (the oldest shark) was first detected in Bimini in 1989 with one offspring (sampled as a 1-

132 year old in 1990), so could have pupped in the years prior to sampling efforts. Further, our age

133 estimates are based on a minimum age at first parturition of 14 years. Of the six known-aged

134 sharks in Feldheim et al.'s (2014) genetic pedigree, the range of ages of first parturition in

135 Bimini was 14-17 years, although we cannot be sure they only gave birth in the Bimini nurseries.

136 Accurate age and life span information are an important component of any demographic

137 modeling, as maximum age and age at maturity are often used to estimate instantaneous rates of

138 natural mortality (Simpfendorfer et al., 2005), as well as, intrinsic rebound potentials and

139 population doubling times (Simpfendorfer 2005, Smith et al., 1998). This study was limited to

140 aging only female $N$. brevirostris. However, previous longevity studies have shown maximum Author to whom correspondence should be addressed: jillbrooks85@gmail.com Tel. +1 6136005895 
141 ages of females are greater than those of males in numerous shark species (Carlson \& Parsons,

142 1997; Driggers et al., 2004). In addition, it is pertinent to note that for population modelling,

143 female life history parameters are considered more relevant as total lifetime fecundity and

144 mortality determine population numbers (Bishop et al., 2006). Intrinsic rebound potential is a

145 demographic parameter that gives a population's productivity after removal of a proportion of

146 the population, and can be useful for understanding the status of exploited populations (Au et al.,

147 2015). Rebound potential is easily calculated for a given total mortality, needing only age at

148 maturity and natural mortality for a given species (Au et al., 2015). Then et al (2014) concluded

149 that from over 200 direct estimates of natural mortality rates, using a maximum-age based

150 estimator performs the best among all estimators evaluated. Previous intrinsic rebound

151 calculations have incorporated the longevity estimate of 25 years for N. brevirostris (Smith et al.,

152 1998), or Hoenig's (1983) formula for natural mortality rates (which also uses the maximum age

153 of 25 years). With this updated minimum longevity, the estimated natural mortality rate

$154\left(\mathrm{M}=4.899 * \operatorname{tmax}^{-0.916}\right)$ for $N$. brevirostris has decreased from $0.257 \mathrm{yr}^{-1}$ to $0.179 \mathrm{yr}^{-1}$ (Then et al.,

155 2014). This increase in life span could mean an increase in the time it takes an exploited

156 population to rebound back to stable numbers.

157 Although there is evidence of gene flow amongst N. brevirostris Northern Hemisphere

158 populations (Ashe et al., 2015) and telemetry data indicating connectivity between the USA and

159 the Bahamas (unpublished data), the genes related to longevity have not yet been identified so

160 we cannot be certain that the longevity found in this study applies throughout their entire

161 distribution. This study may prove difficult to replicate in other species but highlights the

Author to whom correspondence should be addressed: jillbrooks85@gmail.com Tel. +1 6136005895 
162 advantage and importance of long-term, standardized tagging projects, and the collection and

163 analysis of genetic samples for life-history parameter research.

This research was supported by the National Science Foundation Biological Oceanography

166 Program under grants OCE-0623283 to S.H.G. and K.A.F. and OCE 97-12793 to S.H.G., by a

167 grant to D.D.C. from The Pew Charitable Trusts, and a Keystone grant to T.L.G and S.H.G from

168 the Save Our Seas Foundation. We would also like to acknowledge the Guy Harvey Ocean

169 Foundation and Bimini Biological Field Station Foundation for additional funding. Genetic data

170 were collected in the Field Museum's Pritzker Laboratory for Molecular Systematics and

171 Evolution operated with support from the Pritzker Foundation. We gratefully acknowledge the

172 support of Twin Vee and Sundance Boats, Mercury Motors, and Davey Marine. We are grateful

173 to the numerous principal investigators, staff and volunteers that aided in field collections at the

174 Bimini Biological Field Station Foundation over the period 1990-2015. We thank M. Braynen,

175 Director of the Bahamas Department of Fisheries, for issuing a scientific permit in support of our 176 research.

Andrews, A. H., Natanson, L. J., Kerr, L. A., Burgess, G. H., \& Cailliet, G. M. (2011). Bomb radiocarbon and tag-recapture dating of sandbar shark (Carcharhinus plumbeus). Fishery Bulletin 109(4), 454-465.

Author to whom correspondence should be addressed: jillbrooks85@gmail.com Tel. +1 6136005895 
Ashe, J. L., Feldheim, K. A., Fields, A. T., Reyier, E. A., Brooks, E. J., O’Connell, M. T., Gruber, S. H. \& Chapman, D. D. (2015). Local population structure and context-dependent isolation by distance in a large coastal shark. Mar Ecol Prog Ser, 520, 203-216.

Au, D. W., Smith, S.E. \& Show, C. (2015) New Abbreviated Calculation for Measuring Intrinsic Rebound Potential in Exploited Fish Populations- Example for Sharks. Canadian Journal of Fisheries and Aquatic Sciences 72, 767-773 doi: 10.1139/cjfas-2014-0360.

Beamish, R. J. \& McFarlane, G. A. (1983). The Forgotten Requirement for Age Validation in Fisheries Biology. Transactions of the American Fisheries Society 112(6), 735-43.

Bishop, S. D. H., Francis, M. P., Duffy, C., \& Montgomery, J. C. (2006). Age, growth, maturity, longevity and natural mortality of the shortfin mako shark (Isurus oxyrinchus) in New Zealand waters. Marine and Freshwater Research 57(2), 143-154.

Brown, C. A. \& Gruber, S. H. (1988). Age Assessment of the Lemon Shark, Negaprion Brevirostris, Using Tetracycline Validated Vertebral Centra. Copeia 3, 747-53.

Cailliet, G. M., Smith, W. D., Mollet, H. F., \& Goldman, K. J. (2006). Age and growth studies of chondrichthyan fishes: the need for consistency in terminology, verification, validation, and growth function fitting. In Special Issue: Age and Growth of Chondrichthyan Fishes: New Methods, Techniques and Analysis (pp. 211-228). Springer Netherlands.

Cailliet, G. M., \& Andrews, A. H. (2008). Age-validated longevity of fishes: its importance for sustainable fisheries. In 5th world fisheries congress, 103-120.

Campana, S. (2001). Accuracy, Precision and Quality Control in Age Determination, Including a Review of the Use and Abuse of Age Validation Methods. Journal of Fish Biology 59, 197242.

Carlson, J. K., \& Parsons, G. R. (1997). Age and growth of the bonnethead shark, Sphyrna tiburo, from northwest Florida, with comments on clinal variation. Environmental Biology of Fishes 50(3), 331-341.

Carlson, J. K., Hale, L. F., Morgan, A., \& Burgess, G. (2012). Relative abundance and size of coastal sharks derived from commercial shark longline catch and effort data. Journal of fish biology, 80(5), 1749-1764.

Compagno, L. J. V. 1984. FAO species catalogue: sharks of the world. Food and Agriculture Organization of the United Nations, Rome, Italy. 
DiBattista, J. D., Feldheim, K. A., Thibert-Plante, X., Gruber, S. H. \& Hendry, A. P. (2008). A Genetic Assessment of Polyandry and Breeding-Site Fidelity in Lemon Sharks. Molecular ecology 17, 3337-3351.

Driggers, W., Carlson, J., Cullum, B., Dean, J., \& Oakley, D. (2004). Age and growth of the blacknose shark, Carcharhinus acronotus, in the western North Atlantic Ocean with comments on regional variation in growth rates. Environmental Biology of Fishes 71(2), 171-178.

Feldheim, K. A., Gruber, S. H., \& Ashley, M. V. (2002). The breeding biology of lemon sharks at a tropical nursery lagoon. Proceedings of the Royal Society of London B: Biological Sciences 269, 1655-1661.

Feldheim, K. A., Gruber, S. H., DiBattista, J. D., Babcock, E. A., Kessel, S. T., Hendry, A. P., Pikitch, E. K., Ashley, M. V. \& Chapman, D. D. (2014). Two Decades of Genetic Profiling Yields First Evidence of Natal Philopatry and Long-Term Fidelity to Parturition Sites in Sharks. Molecular ecology 23, 110-17.

Francis, M. P., Campana, S. E. \& Jones, C. M. (2007). Age under-estimation in New Zealand porbeagle sharks (Lamna nasus): is there an upper limit to ages that can be determined from shark vertebrae? Marine and Freshwater Research 58, 10-23.

Goldman, K. J. (2005). 6. Age and growth of elasmobranch fishes. Management techniques for Elasmobranch fisheries 474, 76.

Gruber, S. H., De Marignac, J. R. C. \& Hoenig, J. M. (2001). Survival of Juvenile Lemon Sharks at Bimini, Bahamas, Estimated by Mark-Depletion Experiments. Transactions of the American Fisheries Society 130, 376-84.

Hamady, L. L., Natanson, L. J., Skomal, G.B. \& Thorrold, S. R. (2014). Vertebral Bomb Radiocarbon Suggests Extreme Longevity in White Sharks. PLoS ONE 9, e84006. doi:10.1371/journal.pone.0084006

Hoenig, J. M. (1983). Empirical Use of Longevity Data to Estimate Mortality Rates. Fisheries Research 81, 898-903.

Hoenig, J. M., \& Gruber, S. H. (1990). Life-history patterns in the elasmobranchs: implications for fisheries management. NOAA Technical Report NMFS 90(1), 16.

Kessel, S. T., Chapman, D. D., Franks, B. R., Gedamke, T., Gruber, S. H., Newman, J. M., White, E. R., \& Perkins, R. G. (2014). Predictable temperature-regulated residency, movement and migration in a large, highly mobile marine predator (Negaprion brevirostris). Marine ecology progress series, 514, 175-190.

Author to whom correspondence should be addressed: jillbrooks85@gmail.com Tel. +1 6136005895 
64

65

66

67

68

Kohler, N. E., Casey, J. G. \& Turner, P. A. (1998). NMFS Cooperative SharkTagging Program, 1962-93: An Atlas of Shark Tag and Recapture Data. Marine Fisheries Review 60(2), 1-87.

Shiffman, D. S., and N. Hammerschlag. 2014. An assessment of the scale, practices, and conservation implications of Florida's charterboat-based recreational shark fishery. Fisheries 39:395-407.

Simpfendorfer, C. A., BonfilB, R., \& Latour, R. J. (2005). Chapter 8. Mortality estimation. Management Techniques for Elasmobranch Fisheries, FAO FISHERIES TECHNICAL PAPER, 474, 165-186.

Simpfendorfer, C. A. (2005). Chapter 9. Demographic models: life tables, matrix models and rebound potential. Management Techniques for Elasmobranch Fisheries, FAO FISHERIES TECHNICAL PAPER, 474, 187-204.

Smith, S. E., Au, D. W., \& Show, C. (1998). Intrinsic rebound potentials of 26 species of Pacific sharks. Marine and Freshwater Research 49(7), 663-678.

Then, A. Y., Hoenig, J. M., Hall, N. G. \& Hewitt, D. A. (2014). Evaluating the predictive performance of empirical estimators of natural mortality rate using information on over 200 fish species. ICES Journal of Marine Science 72, 82-92. doi: 10.1093/icesjms/fsu136

Wang, J. (2004). Sibship Reconstruction From Genetic Data With Typing Errors. Genetics 166, 1963-79.

Author to whom correspondence should be addressed: jillbrooks85@gmail.com Tel. +16136005895 